\title{
A Formation Mechanism of Transverse Cracks on CC Slab Surface
}

\author{
Shinzo HARADA, ${ }^{1)}$ Shigenori TANAKA, ${ }^{2)}$ Hideyuki MISUMI,3) Shozo MIzOGUCH(2) and Hiroshi \\ HORIGUCHI4)
}

1) Oita Works, Nippon Steel Corporation. Now at Sangyo Shinko Co. Ltd., Nishinosu, Oita, Oita-ken, 870 Japan.

2) Oita Works, Nippon Steel Corporation. Now at Steelmaking Technology Laboratory, R \& D Labs.-1il, Nippon Steel Corporation, Kimitsu, Chiba-ken, 299-11 Japan. $\quad 3$ ) Oita Works, Nippon Steel Corporation. Now at Oita R \& D Lab., Nippon Steel Corporation, Nishinosu, Oita, Oitaken, 870 Japan. $\quad$ 4) Oita Works, Nippon Steel Corporation. Now at Yoshikawa Kogyo, Co. Ltd., Ogura, Yahatahigashi-ku, Kitakyushu, Fukuoka-ken, 850 Japan.

(Received on August 14, 1989; accepted in the final form on October 13, 1989)

\begin{abstract}
Transverse surface cracks were metallorgaphically investigated and the local segregation was found to be the origin of transverse surface cracks on continuously cast slabs. The positive segregation spreaded over an oscillation mark and showed high phosphorous content. At the same time, the sharp negative segregation was also seen adjacent to the positive segregation along the mark. This positive segregation penetrated deeply into austenite grain boundaries, through which transverse cracks propagated. The fractured surface was smooth and the precipitates of $\mathrm{MnS}$ was found.

Based on the observation, a mechanism of the formation of cracks was proposed. At the meniscus, when the tip of partially solidified shell is bent down periodically during mould oscillation, interdendritic "dirty" liquid is squeezed out and accumulated at the valley of an oscillation mark. In other case, bulk liquid overflows on the tip of the shell and again interdendritic "dirty" liquid spreads out and accumulates there. In any case, the local segregation forms at the valley of an oscillation mark. The cracks lead to initiate at this weak part of the shell under any external stresses. Thus so called internal cracks forms below the oscillation mark and propagates along austenite grain boundaries. Finally a large transverse crack forms on the above-mentioned defect. Some industrial measure were summarized to prevent both the segregation and the cracks to form.
\end{abstract}

KEY WORDS: transverse crack; corner crack; segregation; oscillation mark; sweating; continuous casting; slab; steel; mechanism.

\section{Introduction}

Transverse cracks are very common in continuous casting of steel. They are present along oscillation marks on the wide and narrow faces or at the corners of cast slabs. There are many works of investigation on the formation mechanism of this type of cracks. First, hot ductility of as cast steel was shown to be very low at about $1173 \mathrm{~K}\left(900^{\circ} \mathrm{G}\right)$ due to $\gamma / \alpha$ transformation. ${ }^{1)}$ This temperature range is often encountered on the surface of slabs at the unbending point of a caster. Secondly, the crack is related to the oscillation marks and the formation mechanism of oscillation marks is the original concern. There are two types of explanation. One is that the tip of solid shell is periodically bent down at the meniscus. The other is that liquid metal overflows onto the tip of solid shell. However, the driving force is thought different by different workers and clasified as follows.

(1) The periodical inflow of liquid slag during a negative strip time of mould oscillation. ${ }^{2)}$

(2) The periodical inflow of liquid slag during a positive strip time of mould oscillation. ${ }^{3}$ )

(3) The periodical push by solid slag rim during a negative strip time of mould oscillation. ${ }^{4}$

In order to clarify the mechanism, further investigation is necessary in more detail. Anzai et al. ${ }^{5)}$ and
Tada et al. ${ }^{6)}$ calculated the change in pressure in the liquid slag film and showed the possibility of the first mechanism. Tanaka et al. ${ }^{7,8)}$ observed the positive and negative segregation along the oscillation mark and proposed two types of the mechanism. Takeuchi and Brimacombe ${ }^{9)}$ extended further the investigation and analysed quantitatively the heat flow and the pressure in the liquid film of mould flux. They observed two types of oscillation mark. One is with a subsurface hook and the other without it. They concluded that due to an overflow of liquid steel onto the shell, the local delay of solidification became the cause for the former type and due to a negative pressure in the liquid film of mould flux, the penetration of interdendritic liquid was the cause to the latter.

Later, other workers also observed the formation of surface segregation of phosphorous along transverse cracks. ${ }^{10)}$ However, the phenomena of the formation of surface segregation and the initiation of cracks has not yet been clear.

So, the purpose of the present paper is to add some more information and finally to provide industrial measures for the prevention of transverse cracks.

\section{Method of Experiment}

Aluminium killed or aluminrim-silicon killed steel 
of 0.05 to 0.16 mass $\% \mathrm{C}$ was cast at about $1.2-1.4$ $\mathrm{m} / \mathrm{min}$ with a continuous caster of a curved mould type. The size of a mould was $0.252 \times 1.200-1.600$ $\mathrm{m}$. The samples were taken from the surface of a slab and subjected to metallographic investigation. The horizontal, vertical or transverse cross-section of a crack was made and etched by nital, picral, or Oberhoffer's solution. Nital etching reveals a crack and picral etching shows microsegregation clearly, while Oberhoffer's etching makes phosphorous segregation white. The contents of manganese and phosphorous on the spot of segregation were measured by EPMA. The depth of a valley of an oscillation mark was also measured.

\section{Results}

Transverse cracks appear on a wide face and a narrow face or at a corner of a slab. Each type has a common feature and extends along the valley of an oscillation mark.

Fig. 1 shows the effect of components on the total length of transverse wideface cracks per $10 \mathrm{~m}$ of a slab. From this figure, cracks are formed frequently in the range of $0.11-0.16$ mass $\% \mathrm{C}$ and of $\mathrm{Mn} / \mathrm{S}<80$. This is very interesting because the "dangerous" range is exactly the same for longitudinal cracks. ${ }^{13)}$ In addition, niobium strongly enhances the crack sensitivity. This effect is well known on hot ductility. ${ }^{11,12)}$

Fig. 2 is the set of pictures for a small transverse crack on a narrow face. Figs. 2(1) and 2(2) give a comparison of the same cross-section perpendicular to the surface, etched with two kinds of etchant. A crack open to the surface is seen just at the depression of an oscillation mark. A few black lines also exist in the subsurface region. However, note that a line of microsegregation in the region " $\mathrm{B}$ " in Fig. 2(2) does not have its counterpart in the same region " $\mathrm{A}$ " in Fig. 2(1). This is more clearly seen in the enlarge-

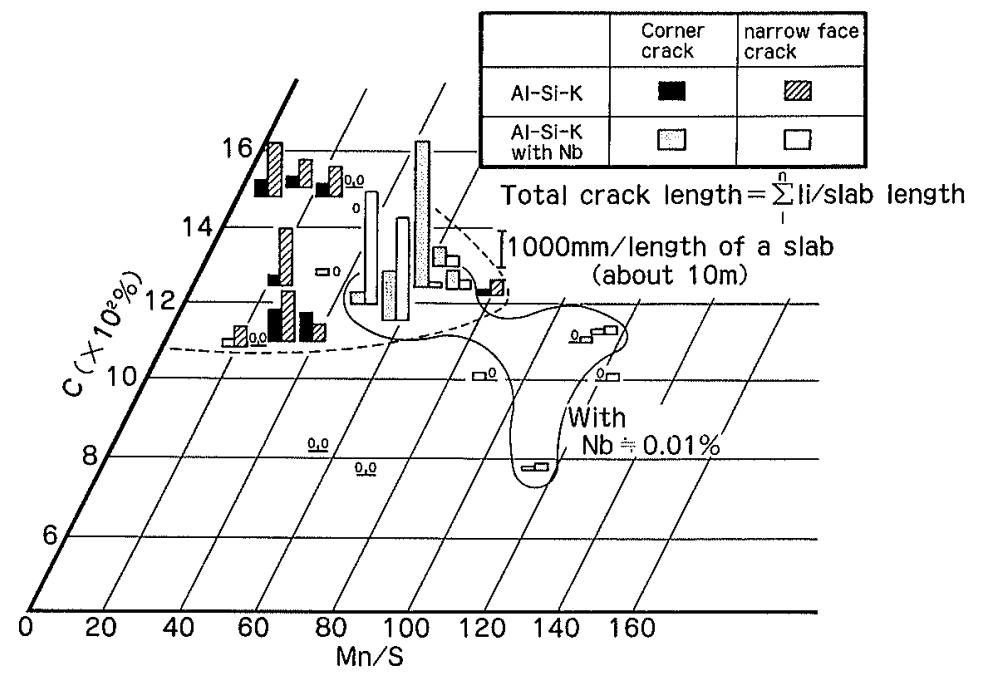

Total crack length is the sum of each crack, $l_{i}$, per slab.

Fig. 1. Relation between the frequency of transverse crack formation and the steel composition. ment of these photographs, Figs. 2(3) and 2(4). Since this line of segregation is not detected with nital etchant, it should not be a crack but just a microsegregation.

On the other hand, a line marked " $\mathrm{G}$ " is a crack because it is seen in both pictures of nital and picral etching. In order to confirm this, a fractography was made. Fig. 3 shows the result exactly for the same specimen. In Fig. 3(1), two lines of microsegregation are seen, marked " $B$ " and " $C$ ", just the same as Fig. 2(2). Figs. 3(2) and 3(3) show the fractured surfaces. Both surfaces are relatively smooth and are the typical examples of the fracture of liquid film. ${ }^{14}$ ) However, in " $\mathrm{B}$ ", some precipitates of $\mathrm{MnS}$ exist. This indicates that $\mathrm{MnS}$ finally crystallized after the crack was healed by a highly segregated liquid.

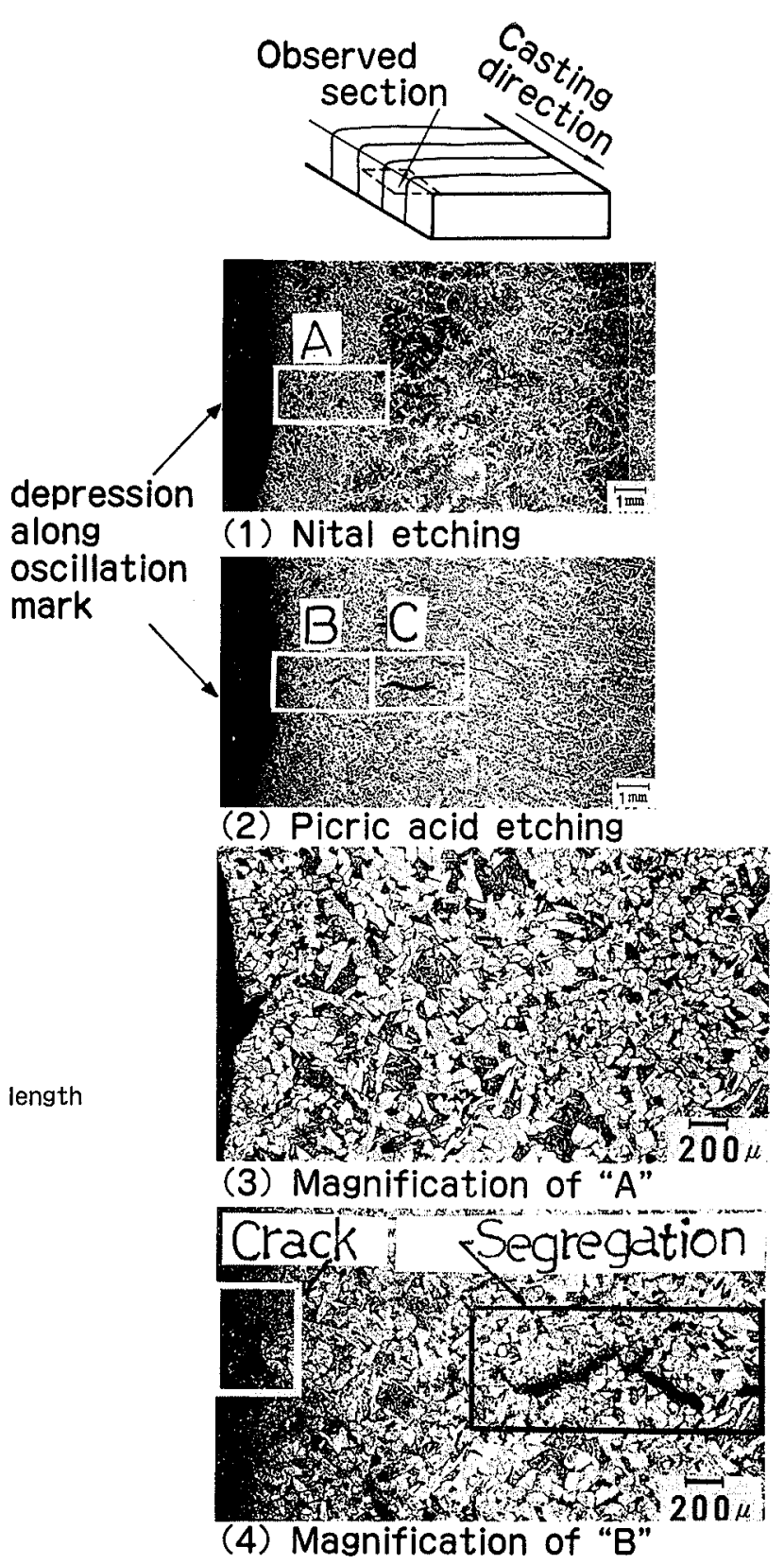

Fig. 2.

Small transverse cracks at the valley of an oscillation mark. 

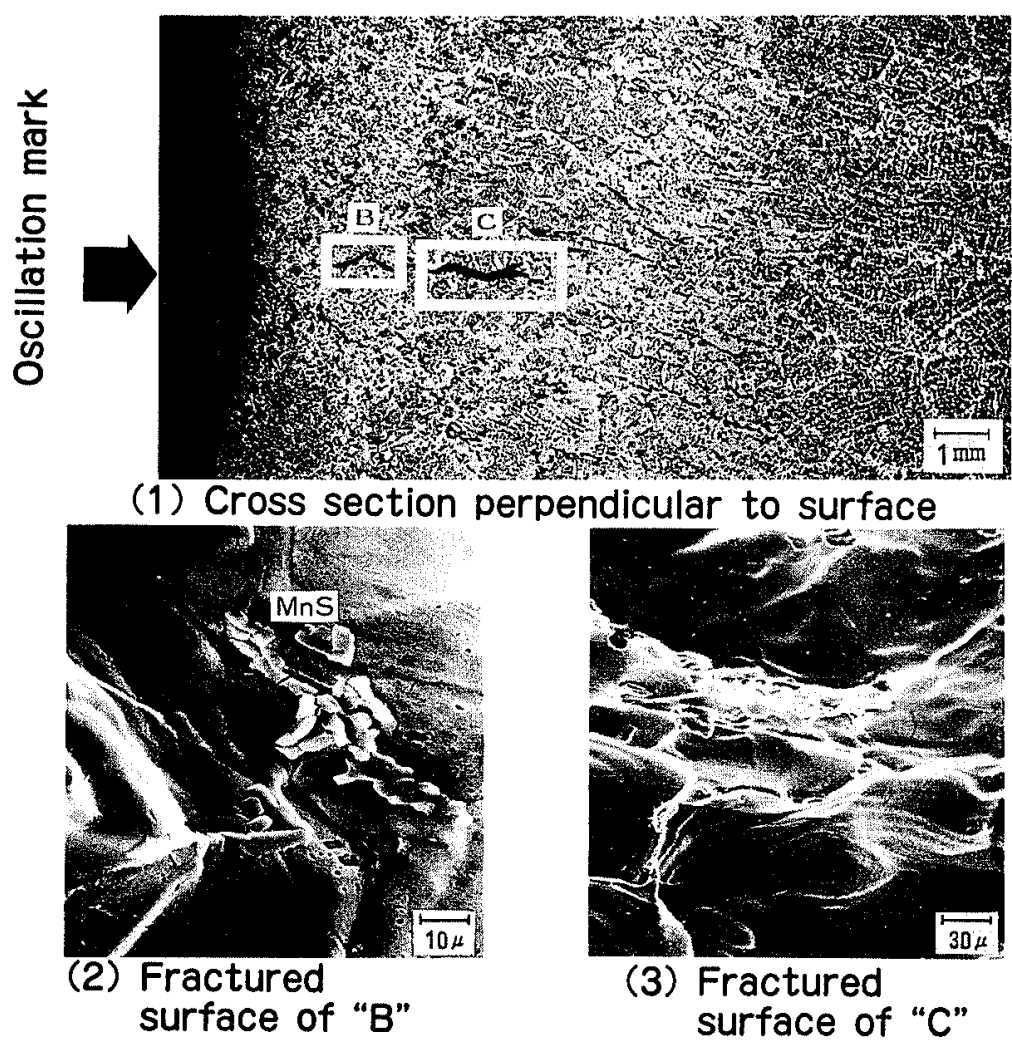

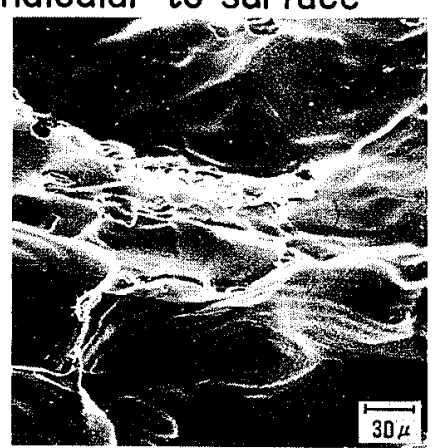

(3) Fractured surface of " $\mathrm{C}$ "
Fig. 3.

Fractured surface of the cracks shown in Fig. 2.

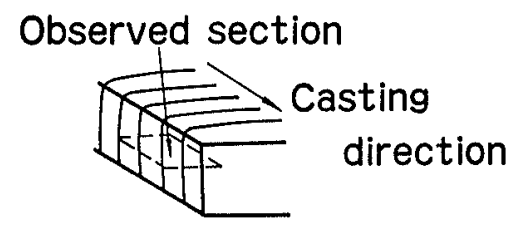

Fig. 4.

Large transverse crack on a narrow face.

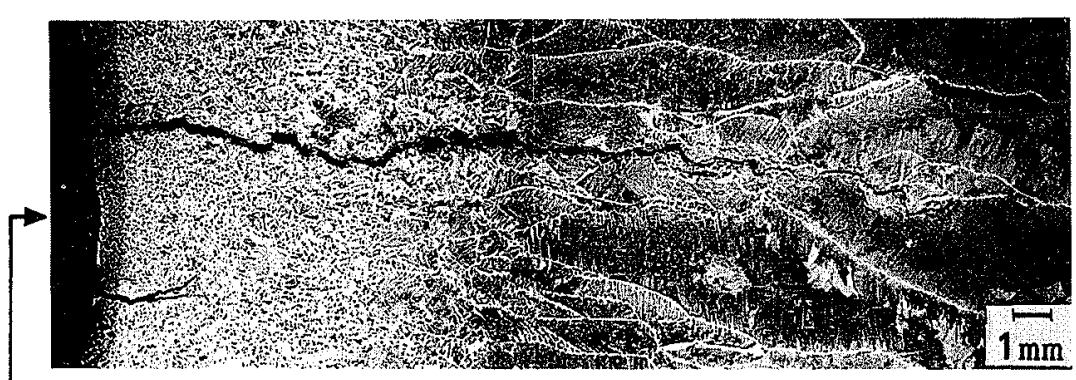

(1) Nital etching

depression along oscillation mark

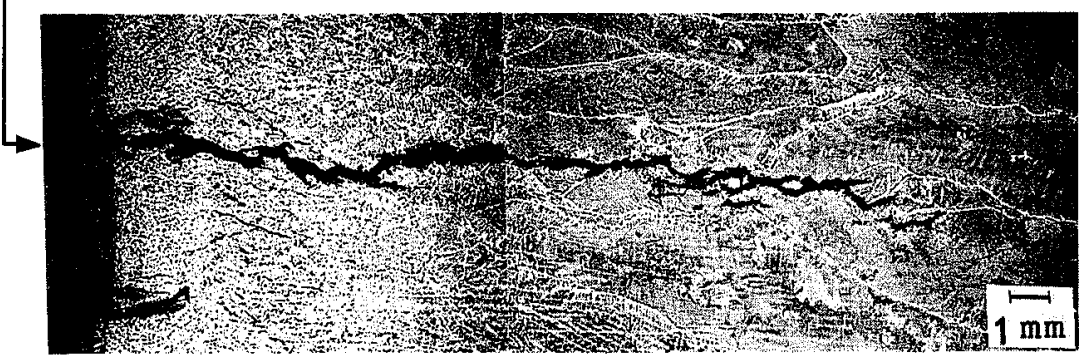

(2) Picric acid etching
This is a similar phenomenon observed for internal cracks. ${ }^{14)}$ So, the line of microsegregation like " $\mathrm{B}$ " is a healed crack (not open) which is a kind of internal crack. On the other hand, a crack like " $G$ " is a real crack which opens up again after healing.

Fig. 4 shows the example of very large cracks on a narrow face. This figure also gives a comparison of the same cross-section etched with two kinds of etchant. In this case, a crack deeply propagates into the austenite grain boundaries below the valley of an oscillation mark. The black lines of picral etching as in Fig. 4(2) are wider and longer than that of nital etching. So, this indicates that cracks propagate through microsegregation area. The features of transverse facial cracks are summarized as follows.

(1) There are some localizad microsegregations in 
the subsurface region below the valley of oscillation marks.

(2) The segregation area penetrates deeply into the austenite grain boundaries.

(3) Cracks propagate through the segregation area.

(4) Cracks have the similar feature of fracture as the common internal cracks.

Next, the features of transverse corner cracks are described. Fig. 5 shows the oscillation mark in the polished horizontal cross-section just on the corner of a slab. A strong segregation is seen along the mark. Note that a positive segregation (black area) spreads broadly above the sharp negative segregation (white line) along the mark. Fig. 6 is the set of pictures of
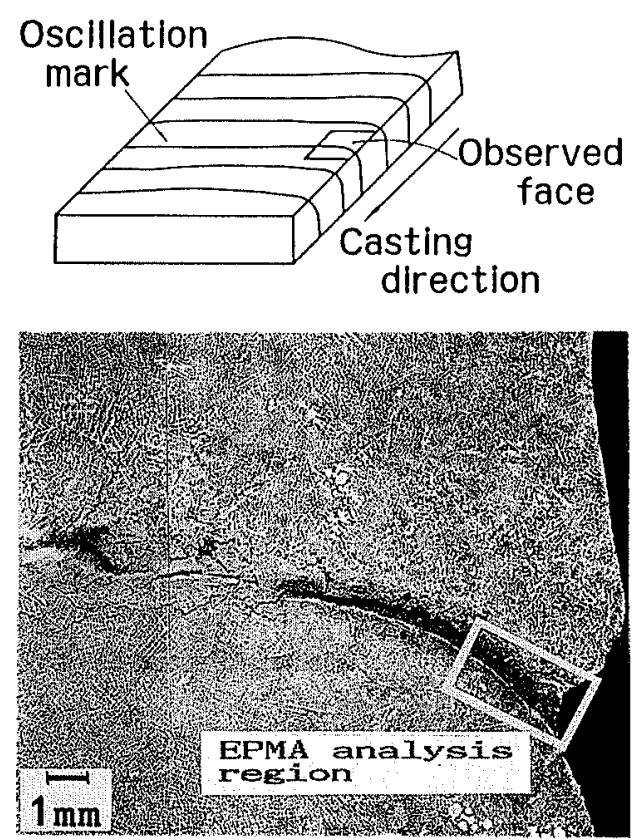

Fig. 5. Segregation along an oscillation mark.
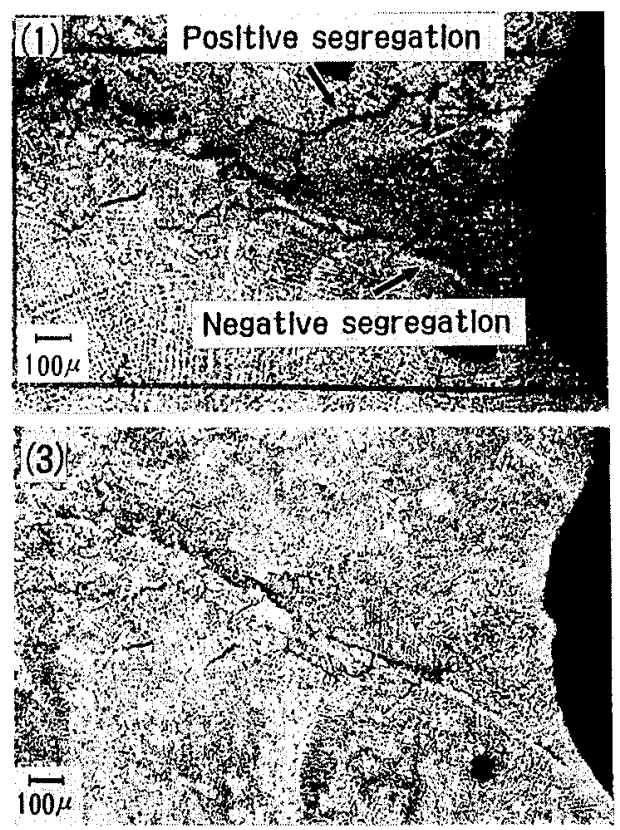

(1) Picric acid etching

(2) Oberhoffer's etching the same area as that of the white rectangle in Fig. 5. Figs. $6(1)$ to $6(3)$ are the pictures made with picral, Oberhoffer's and nital etchants, respectively. Fig. 6(4) shows some cracks on the same cross-section before etching. The positive segregation which looks black lines in both nital and picral etching exactly corresponds to that which looks white lines in Oberhoffer's etching. It is known that Oberhoffer's etching reveals the microsegregation of phosphorous as the white region. So, the element of this positive segregation along the oscillation mark should be phosphorous. The detailed analysis was made by EPMA. Fig. $7(1)$ is the same region of the analysis as in Fig. 6. Figs. $7(2)$ and $7(3)$ are the results of mapping analysis of concentrations of phosphorous and manganese. The microsegregation of phosphorous is clear along the mark and its peak value is 0.28 mass $\%$, almost 17 times higher than that of the ladle content. The cracks are also found to correspond to the region of phosphorous segregation comparing these pictures. Again, as previously mentioned, the crack propagates through the region of microsegregation, particularly of phosphorous.

Such segregation of phosphorous has a relation with a depth of oscillation marks as shown in Fig. 8. A strong effect is seen for medium carbon steel while little effect for low carbon steel. The depth of oscillation marks is strongly dependent on the mode of oscillation. Fig. 9 shows the relation between depth and healing time, or so called negative strip time. For both the different stroke of oscillation, the depth is linearly dependent of healing time. The even stronger tendency has been reported. ${ }^{101}$

\section{Discussion}

The origin of cracks is the microsegregation. The mechanism of the formation of the surface segrega-
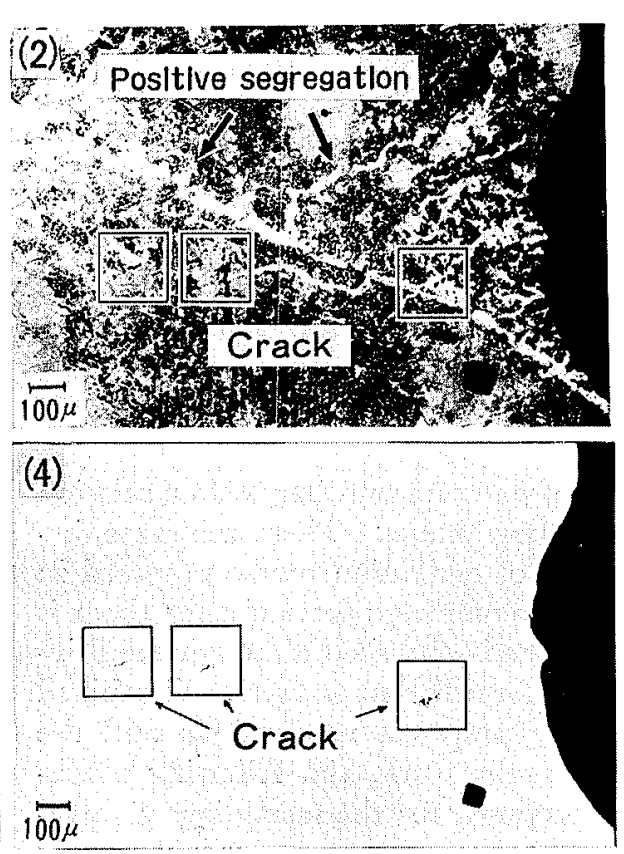

(3) Nital etching

(4) Polished surface before etching

Fig. 6. Segregation and cracks along the mark. Enlargement of Fig. 

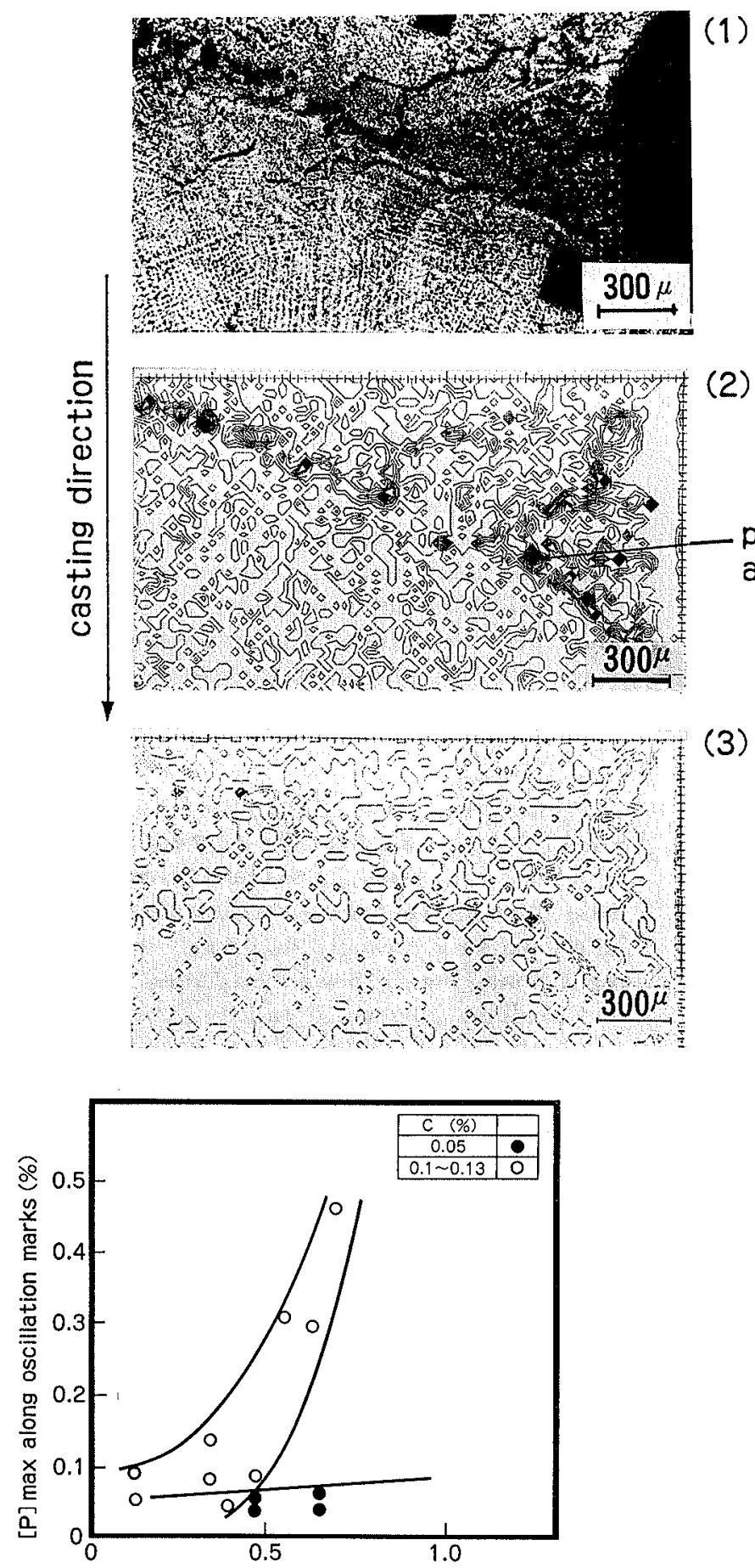

Depth of oscillation marks (mm)

Fig. 8. Relation between the segregation of phosphorous and the depth of oscillation marks.

tion, particularly of phosphorous, has a close relation with that of oscillation marks. There are some formation mechanisms of oscillation marks proposed in the literature. The common aspect among them is the deformation of semi-solid shell although the driving force is different for different workers. Combined with the previously proposed mechanisms and the findings in the present work, the following mechanisms are now proposed for the formation of segregation along oscillation marks, as illustrated in Fig. 10.

The first mechanism relates to the deformation of
EPMA

analysis

region

(3) $[\mathrm{Mn}]$ analysis

division

: $0.126 \%$

Fig. 7. EPMA analysis of segregation shown in Fig. 6.
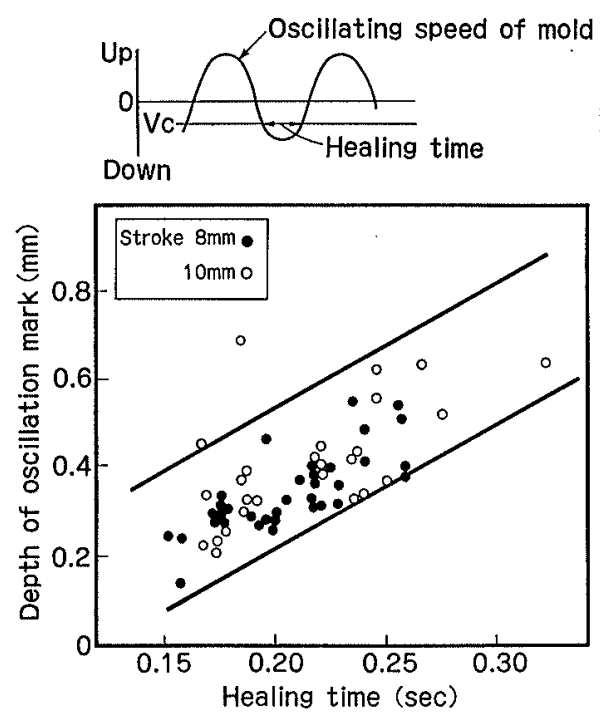

Fig. 9. Relation between the depth of oscillation marks and the healing time.

the semi-solid shell. When an oscillation mark is formed, i.e., when the partially solidified shell is deformed, the " dirty" segregated liquid steel between dendrite arms is squeezed out to the surface. Then, the positive segregation occurs and speads broadly on the tip of the shell. After squeezing out the "dirty" liquid, the rest of the semi-solid shell becomes "cleaner" and solidifies rapidly. By the deformation, the iso-solid-fraction lines in the shell become closer to 
each other. The sharp negative segregation as seen in Fig. 2 is thus explained.

The second mechanism relates to the overflow of the bulk liquid onto the tip of the shell. The shell is reheated by the liquid steel that has overflowed onto the tip of the shell. Then the segregated liquid steel between dendrite arms is pumped out to the surface according to the balance of pressure of the liquid steel. Thus the surface segregation is formed even if the above-mentioned deformation of the shell does not occur. This second concept is just the same in principle, as the phenomenon called "sweating" in alminium continuous casting. ${ }^{15)}$ However, the formation of the sharp negative segregation may not be well explained by this mechanism. In other words, there must be two types of oscillation marks. That is either with a sharp segregation or with less segregation along the marks depending on the working mechanism.

In any case, the " dirty" liquid is abundant on the tip of the solidified shell. The severer segregation is expected when the deformation or the overflow is severer. Thus the degree of segregation depends on the depth of oscillation marks as shown in Fig. 8. In order to minimize this, a certain mode of oscillation is recommended, because the depth is determined by the healing time as shown in Fig. 9. In general, the healing time is a function of some parameters. In the case of sinusoidal oscillation, the result of calculation is given in Fig. 11. At the constant withdrawal speed, there is a maximum on the healing time. In order to avoid this range, the higher frequency and smaller stroke are recommended for the mode of oscillation. However, there is another limitation. A minimum negative strip ratio is required beyond which the tendency of break-out may increase. This limit de-

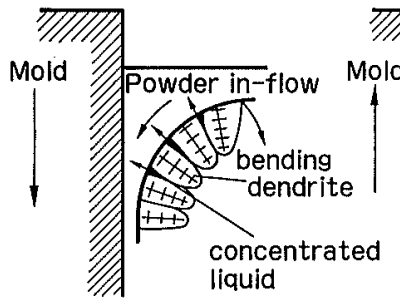

(a) During negative strip period

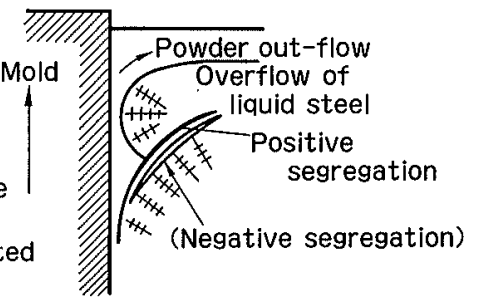

(b) During positive strip period
Fig. 10. Formation mechanism of segregation at the meniscus. pends on some operational conditions such as the quality of mould fluxes etc. and so, the suitable condition should be selected in operation.

Fig. 12 summarizes the sequence of the formation of segregation and transverse crack. The surface segregation starts to form at the meniscus during mould oscillation and propagates into the shell in due course of solidification. The valley of oscillation marks is so "dirty" and the actual solidus temperature for this region is very low due to segregation. So, the semi-solid shell will easily fracture along the segregation. In this context, the similarity between transverse cracks and longitudinal cracks is very remarkable. Longitudinal cracks also accompany surface segregation ${ }^{16)}$ and initiate as internal cracks ${ }^{17)}$ at the subsurface.

Further, at the valley of oscillation marks the heat conduction to the mould is naturally very low and the solidified shell is thinner in this part than in other parts. If any stresses such as frictional stresses, bulging stresses, thermal stresses, etc. act in this state, tensile stresses and strains are generated on the internal surface of this weak part and so called internal cracks may be formed at the subsurface below an oscillation mark. Thus, " healed " cracks are formed consecutively with microsegregation as previously shown in Fig. 2. These "healed" cracks will lead to open later and propagate into austenite grain boundaries if there are strong external stresses such as thermal stresses or stresses due to misalighmment of

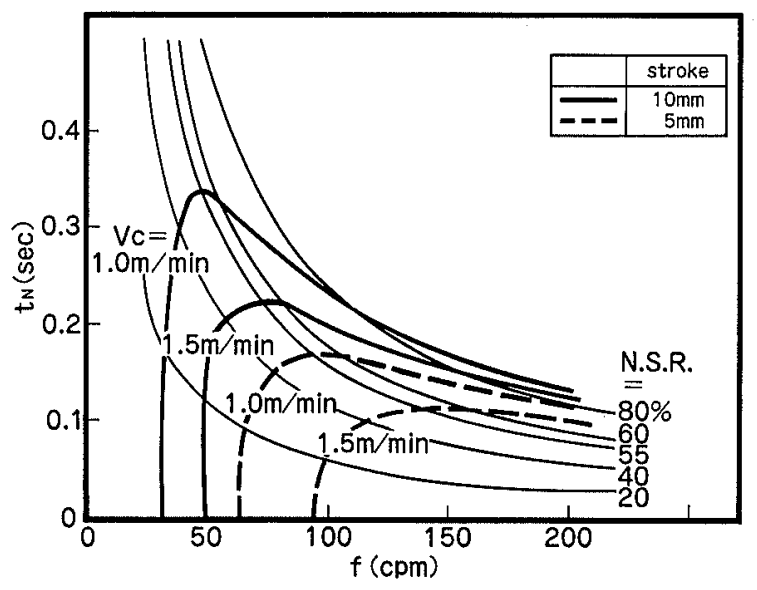

Fig. 11. Relation between the healing time and the frequency of oscillation.

Fig. 12.

Formation mechanism of transverse cracks.

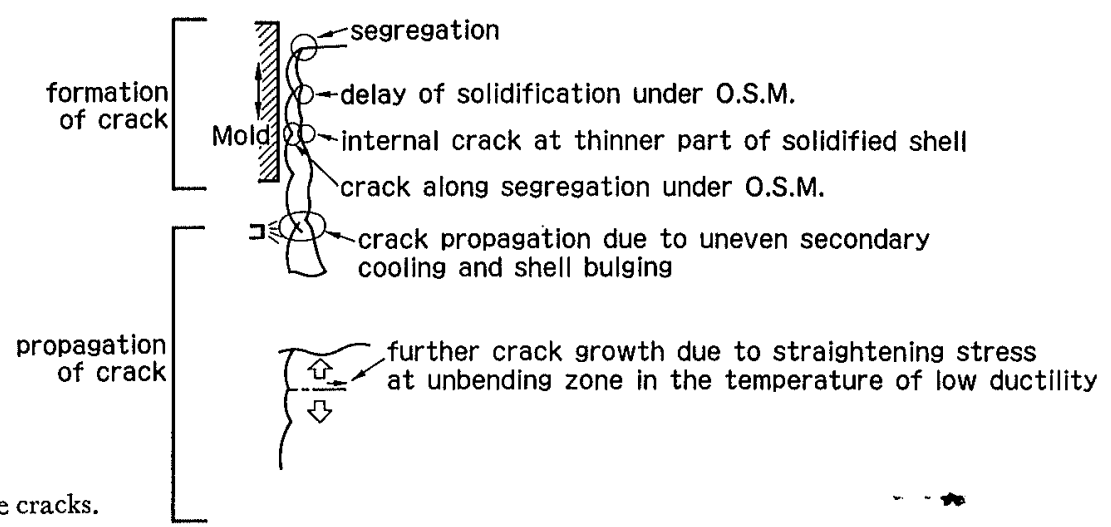


support rolls on a narrow side just below the mould. The example of a very large crack on narrow side shown in Fig. 4 is thus explained.

When the surface temperature along the mark reaches $973-1173 \mathrm{~K}$, the low-ductility zone associated with $A r_{3}$ transformation appears and crack sensitivity increases. If this happens at the tangential point of a caster, the effects are superimposed and severe crack formation should be observed. The valley of oscillation marks also provides the notch effect for the cracks to open to the surface.

From the above-mentioned discussion, the countermeasures to prevent these transverse cracks are divided into two parts, the prevention of the formation of segregation that initiates cracks and the prevention of crack propagation. They are summarized as follows.

\section{Measures to Prevent Segregation}

(1) The uniform solidification at the beginning is vital. Slow cooling rather than rapid cooling at the meniscus is recommend and the smoothness of the mould surface should be maintained. ${ }^{13,16}$ )

(2) The higher frequency and smaller stroke for the mode of oscillation is chosen within the accepted range in operation in order to decrease the depth of the valley of oscillation marks.

(3) With respect to steel compositions, 0.10-0.15 mass $\% \mathrm{G}$ is avoided if possible, and the phosphorous ${ }^{10}$ ) and sulphur contents are reduced. The value of $\mathrm{Mn} / \mathrm{S}$ over 80 is desirable.

\section{Measures to Prevent Crack Propagation}

(1) Constraint forces acting on the solidified shell in the mould are reduced. Desirable measures include the use of mould fluxes of good lubrication properties, ${ }^{18}$ optimization of the taper of narrow sides, ${ }^{19)}$ and uniform mould cooling.

(2) Thermal stresses are reduced by uniform slow cooling as the secondary cooling just below the mould. ${ }^{20)}$

(3) Abnormal stresses and bulging are avoided as far as possible by making the slab supporting force appropriate. ${ }^{20)}$

(4) Stresses and strains are minimized at the slab bending and straightening point.

(5) A secondary cooling pattern is adopted by which the low ductility zone for high-temperature strength of steel is avoided at the bending and unbending point. For example, the surface temperature range of $973-1173 \mathrm{~K}$ is avoided. ${ }^{20}$ )

\section{Conclusion}

The local segregation was found to be the origin of transverse crack on GG slabs surface and a mechanisms was proposed. The "dirty" liquid is accumulated on the tip of solidified shell during the healing time of mould oscillation. The cause of this accumulation may be either the deformation of the tip of partially solidified steel or the overflow of bulk steel. Based on this findings, some industrial measures are summarized for the prevention of transverse cracks in GG process.

\section{REFERENCES}

1) H. Suzuki, T. Nishimura and S. Yamaguchi: TetsuntoHagané, 65 (1979), 2038.

2) T. Emi, H. Nakato, Y. Tida, K. Emoto, R. Tachibana, T. Imai and H. Bada: Steelmaking Proceedings, Vol. 61, ISS-AIME, Penn., (1978), 351.

3) K. Kawakami, T. Kitagawa, H. Mizukami, H. Uchibori, S. Miyahara, M. Suzuki and Y. Shiratani: Tetsu-lo-Hagané, 67 (1981), 1190.

4) P. V. Riboud, M. Oletto, J. Leclerc and W. Pollak: Steelmaking Proceedings, Vol. 61, ISS-AIME, Penn., (1978), 411.

5) S. Anzai, T. Shigezumi, T. Nishitani and T. Ando: Tetsuto-Hagané, 69 (1983), S1038.

6) K. Tada, J-P. Birat, P. V. Riboud, M. Larrecq and H. Hackl: Tetsu-to-Hagané, 70 (1984), S155; Trans. Iron Steel Inst. Jpn., 24 (1984), B382.

7) S. Tanaka, H. Misumi, S. Mizoguchi and H. Horiguchi: Telsu-to-Hagané, 67 (1981), S172; Trans. Iron Steel Inst. Jpn., 21 (1981), B350.

8) S. Tanaka, H. Misumi, T. Kibe, T. Oota, S. Mizoguchi and H. Horiguchi: Tetsu-to-Hagané, 67 (1981), S852; Trans. Iron Steel Inst. Jpn., 22 (1982), B123.

9) E. Takeuchi and J. K. Brimacombe: Metall. Trans. B, 16B (1985), 605.

10) A. Kuribayashi, I. Ibuki, S. Tokushige, N. Tsuru and S. Miyahara: Tetsu-to-Hagané, 72 (1986), S163.

11) B. Minz and J. Arrowsmith: Met. Technol., 61 (1979), 24.

12) C. Ouchi and K. Matsumoto: Trans. Iron Steel Inst. Jpn., 22 (1982), 181.

13) T. Saeki, S. Ohguchi, S. Mizoguchi, T. Yamamoto, H. Misumi and A. Tsuneoka: Tetsu-to-Hagané, 68 (1982), 1773.

14) E. B. Hawbolt, F. Weinberg and J. K. Brimacombe: Metall. Trans. B, 10B (1979), 229.

15) B. Chalmers: Principles of Solidification, R. E. Krieger Publ. Co., Malbar, FL, (1982), 180.

16) T. Kohno, T. Shima, T. Kuwabara, S. Mizoguchi, T. Yamamoto, H. Misumi and A. Tsuneoka: Tetsu-to-Hagané, 68 (1982), 1765.

17) J. K. Brimacombe, F. Weinberg and E. B. Hawbolt: Metall. Trans. B, 10B (1979), 279.

18) T. Nakano, M. Fuji, K. Nagano, S. Mizoguchi, T. Yamamoto and K. Asano: Tetsu-to-Hagané, 67 (1981), 1210.

19) H. Nakato, M. Ozawa, K. Kinoshita, H. Habu and T. Emi: Tetsu-to-Hagané, 67 (1981), 1200.

20) T. Kohno, T. Shima, T. Kuwabara, T. Yamamoto, M. Wake and A. Tsuneoka: Tetsu-to-Hagané, 68 (1982), 1792. 